\title{
Design of tailor-made chemical blend using a decomposition-based computer-aided approach
}

\author{
Yunus, Nor Alafiza; Gernaey, Krist; Manan, Z.A.; Woodley, John; Gani, Rafiqul
}

Published in:

4th International Conference on Modeling, Simulation and Applied Optimization

Link to article, DOI:

10.1109/ICMSAO.2011.5775572

Publication date:

2011

Document Version

Early version, also known as pre-print

Link back to DTU Orbit

Citation (APA):

Yunus, N. A., Gernaey, K., Manan, Z. A., Woodley, J., \& Gani, R. (2011). Design of tailor-made chemical blend using a decomposition-based computer-aided approach. In 4th International Conference on Modeling,

Simulation and Applied Optimization IEEE. https://doi.org/10.1109/ICMSAO.2011.5775572

\section{General rights}

Copyright and moral rights for the publications made accessible in the public portal are retained by the authors and/or other copyright owners and it is a condition of accessing publications that users recognise and abide by the legal requirements associated with these rights.

- Users may download and print one copy of any publication from the public portal for the purpose of private study or research.

- You may not further distribute the material or use it for any profit-making activity or commercial gain

- You may freely distribute the URL identifying the publication in the public portal 


\title{
Design of Tailor-Made Chemical Blend Using a Decomposition-Based Computer-Aided Approach
}

\author{
Nor Alafiza Yunus ${ }^{\text {a }}$, Krist V. Gernaey ${ }^{\text {a }}$, Zainuddin Abdul Manan ${ }^{\text {b }}$, John M. Woodley ${ }^{\text {a }}$ \\ and \\ Rafiqul Gani*,a \\ ${ }^{\text {a }}$ Department of Chemical and Biochemical Engineering, Søltofts Plads, Building 229, \\ Technical University of Denmark, 2800 Kgs. Lyngby, Denmark. \\ ${ }^{b}$ Process System Engineering Centre (PROSPECT), Faculty of Chemical and Natural \\ Resources Engineering, UTM Skudai, 81310, Johor Bahru, Johor, Malaysia \\ *rag@kt.dtu.dk
}

\begin{abstract}
Computer aided techniques form an efficient approach to solve chemical product design problems such as the design of blended liquid products (chemical blending). In chemical blending, one tries to find the best candidate, which satisfies the product targets defined in terms of desired product attributes (properties).The systematic computer-aided technique first establishes the search space, and then narrows it down in subsequent steps until a small number of feasible and promising candidates remain. At this point, experimental work may be conducted to verify if any or all the candidates satisfy the desired product attributes. Alternatively, rigorous modeling could also be used in this final step. In other words, the candidates are quickly generated and screened until a small number is left for final selection and evaluation by experiments and/or rigorous modeling.
\end{abstract}

This paper presents a design methodology for blended liquid products that identifies a set of feasible chemical blends. The blend design problem is formulated as a Mixed Integer Nonlinear Programming (MINLP) model where the objective is to find the optimal blended gasoline or diesel product subject to types of chemicals and their compositions and a set of desired target properties of the blended product as design constraints. This blend design problem is solved using a decomposition approach, which eliminates infeasible and/or redundant candidates gradually through a hierarchy of (property) model based constraints. This decomposition method reduces the search space in a systematic manner and the general blend design problem is decomposed into two stages. The first stage investigates the mixture stability where all unstable mixtures are eliminated and the stable blend candidates are retained for further testing (note that all blends must be stable liquid mixture). In the second stage, the blend candidates have to satisfy a set of target properties that are ranked according to a specified priority. Finally, a short list of candidates, ordered in terms of specified performance criteria, is produced for final testing and selection. The application of this systematic and computer-aided approach is illustrated through a case study involving the design of blends of gasoline with oxygenated compounds resulting from degradation and fermentation of biomass for use in internal combustion engines. Emphasis is given here on the concepts used and on the validation of the property models, mainly, the Reid vapor pressure model and the liquid phase stability tests.

\subsection{Introduction}

The application of computer-aided design techniques, in molecular and mixture design problems, has been practiced since the 1980s. Computer-Aided Molecular/mixture Design (CAMD) has been used extensively for the design of solvents, polymers, polymeric composites, paints, pesticides, drugs, and also blends $[1,2]$. Computer-aided mixture design, with specified property constraints, was applied to solvent selection, by integrating an optimisation with computer-aided mixture design (CAMD) [3]. Later on, the methodology for computer-aided molecular and mixture design, with specified property constraints, was developed with the aim to predict the nature and properties of molecules, and/or mixtures [4]. In many cases, these methods proved the effectiveness of the computer-aided approach, in the design of molecules and mixtures. However, design of tailor-made chemical blends, dealing with special or new compounds, has not yet been reported.

A tailor-made chemical blend is defined as a mixture of chemicals with specific (derived/target) properties. The mixture is specifically designed for a purpose. Many liquid chemical blends (also known as liquid formulations) are used in daily life, such as detergents, paints, and drugs, were designed for a specific purpose. The traditional method of design, involves difficult and expensive trial-and-error processes. For instance, new drugs often cost millions of dollars and consume several years of development 
time. If the drug does not obtain a marketing license, then all that effort and money is wasted. Chemical selection is an important step in product design, which could enhance the likelihood of developing successful products. Therefore, the role of computer-aided methods and tools is crucial during the early stages of blend design to quickly identify the most suitable candidates and to avoid efforts for infeasible regions of the search space [5].

In this paper, a list of candidates for a specific product has been identified using a decomposition-based computer-aided approach. Based on this approach, the chemical blend problem is solved by solving three smaller sub-problems. Within each sub-problem, design alternatives are screened out through a set of product constraints that must be satisfied. This method is able to handle different types of constraints, such as those related to liquid mixture stability, chemical compositions, and product attributes in the form of target properties, in an efficient way. The remainder of the paper addresses first, the general problem formulation of the tailor-made chemical blend design, and includes a brief explanation of the method used to solve the problem as well. Secondly, a case study involving the design of a gasoline blend is presented to highlight the concepts and the validation of the models employed. Finally, the paper concludes with a summary and suggestions for future work.

\subsection{General Problem Formulation}

The general tailor-made chemical blend problem is formulated as a Mixed Integer Non-Linear Programming (MINLP) problem, where a product performance index is optimised, subject to product attributes (target properties), process specifications and chemical reactions. The mixture properties, such as solubility and stability are very important in liquid blending. This property is evaluated using a liquidphase activity coefficient model. The most commonly used method, to predict the activity coefficient, is by using the UNIFAC group contribution method [6]. Product constraints are related to the product attributes, as defined by consumer needs, local regulations, as well as environmental effects. The product attributes need to translate to a set of target properties, which are denoted as product constraints. Different types of blended products need different sets of target properties, which represent the special qualities of that product. Process models usually consist of mass and energy balance equations and constitutive equations (property models). These process model equations can be represented as equality constraints.

Considering the multiple types of constraint equations, a general tailor-made liquid chemical blend problem is formulated as:

$$
\min / \max f_{o b j}(X, Y)
$$

Subject to

Mixture constraints: $g_{1}(X, Y) \leq 0$

Product property constraints: $g_{2}(X, Y, \emptyset) \leq 0$

Process model constraints: $g_{3}(X, Y)=0$

$f_{o b j}$ is the objective function, defined in terms of blend performance characteristics, and/or cost, which may be minimized or maximized. $\mathrm{Y}$ is a vector of binary integer variables, which is allied to the identities of the chemicals. $\mathrm{X}$ is a vector of continuous variables, which is related to the mixture (compositions), while $\emptyset$ is a vector of process variables, such as temperature and pressure. $g_{1}$ and $g_{2}$ are the mixture property constraints and a set of product property constraints, respectively, while the process model constraints is represented by $g_{3}$.

\subsection{Method of Solution}

There are many ways to solve the blend design MINLP problem. The efficiency of solving these problems usually depends on the problem structure. A simple model, with a large number of variables and constraints, might easily be solved using a modest computational effort; while a complex model much smaller in size might be very difficult to solve [7]. The Generalized Benders Decomposition (GBD) is the earliest algorithm developed by Geoffrion for solving MINLP problems [8]. This method decomposes the problem into two sub-problems: Nonlinear Programming (NLP) sub-problem (overestimator) and Mixed Integer Linear Programming (MILP) master-problem (underestimator). The NLP sub-problem provides the upper bounds by solving the sub-problem with fixed integer variables, while the lower bounds are obtained from MILP master-problem . Another method used for solving MINLP problems is the branch and bound approach. This method enumerates the alternatives by fixing the integer variables and solving the resulting NLP problems for each alternative. This option is feasible only when a small number of alternatives need to be checked. The most common method to solve MINLP problems is the Outer Approximation (OA) technique. The OA technique solves the problem in similar way to GBD, but different in the master problem formulation, which $\mathrm{OA}$ formulates based on primal information and outer linearization. An approach proposed recently [2], decomposes the MINLP problem into sub-problems consisting of a subset of constraints, ordered according to a specific hierarchy. This method is able to manage the complexity of MINLP problems that requires the use of multiple process-property models, highly complex multi-level models and/or having models/data from different sources. For these problems, the decomposition of the constraints according to a specific hierarchy provides a more flexible solution approach. 
In this paper, the approach by Achenie et al. [2] is adopted to solve the general tailor-made liquid chemical blend problem (MINLP model). This problem is decomposed into three sub-problems, and solved accordingly. Sub-problems 1 and 2, only involve the solution of a subset of the constraints from the original set. The last sub-problem solves the objective function and the rest of the MINLP model. The decomposition method removes the infeasible alternatives and redundant combinations, in a systematic way. The first sub-problem deals with mixture stability, which is an important step to ensure that the blended liquid-liquid mixtures are miscible. The phase stability is evaluated from calculated liquid phase activity coefficients, which are predicted using the UNIFAC group contribution method. Then, the second sub-problem consisting of the product target property models, which are a combination of linear and non-linear models, are considered. The linear models are solved first because they are easier to solve. Since the first part eliminates many candidates, therefore, the product property constraints are tested only for miscible candidates thus increasing the chance of determining the optimal blend and computational efficiency. Finally, the last subproblem is solved easily, because a large portion of the search space was removed by solving the earlier sub-problems. This decomposition approach is illustrated in Figure 1.

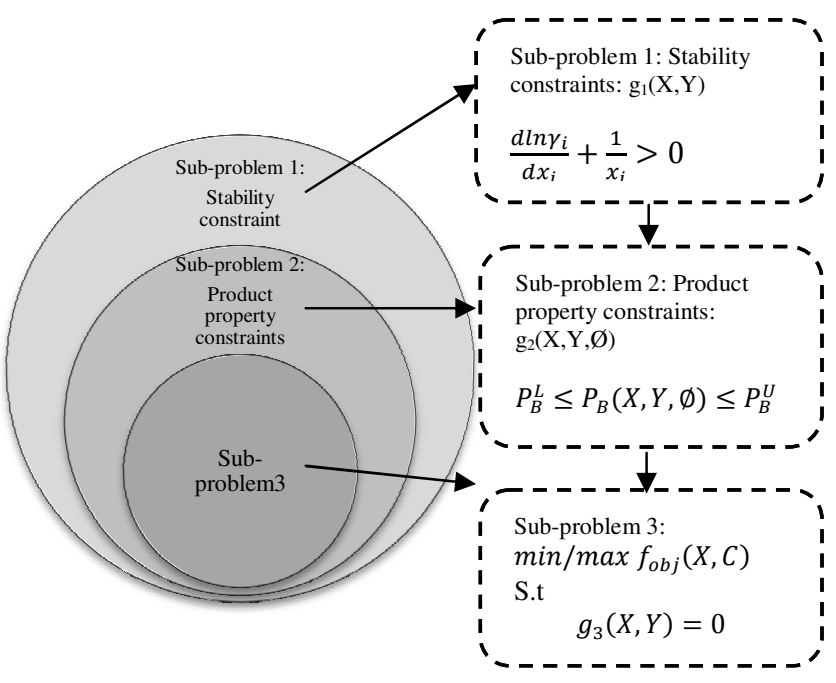

Figure 1: Decomposition of the MINLP problem into sub-problems

\subsection{Case study: Application of blend design method}

The case study involves the design of a gasoline blend with bio-chemicals derived from biomass or other renewable sources. Adding bio-derived chemicals to conventional hydrocarbon fuels for use in a sparkignition engine could enhance the engine efficiency as well as reducing fossil-fuel consumption and $\mathrm{CO}_{2}$ emissions. Three bio-derived chemicals were selected, which are ethanol, butanol and methy tetrahydrofuran
(MTHF). Finding the optimal blend ratio is important in order to get a high fuel efficiency. Therefore, the goal of this study is to design a gasoline blend, which satisfies a set of target properties (see Table 1).

\subsection{Detailed formulation of the problem}

In Table 1 , subscripts $G, B$ and $i$ represent gasoline, blend and $i^{\text {th }}$ chemical, respectively. $C, H H V, O N$, and $W_{o}$ represent the chemical cost, higher heating value, octane number and oxygen percentage, respectively. $P$ and $T$ are the pressure and temperature, respectively. Symbols $\rho_{B}, \mu_{B}$ and $\gamma_{i}$ represent the blend density, dynamic viscosity and activity coefficient of species $i$, respectively. $P_{i}^{\text {sat }}$ is the vapor pressure of pure species $i$ and $x_{i}$ represent mole fraction while $\mathrm{v}_{\mathrm{i}}$ is volume fraction.

Table 1. Model and target value for each mixture property

\begin{tabular}{|l|c|l|c|c|}
\hline \multicolumn{5}{|l|}{ Objective function $f_{\text {obj }}=\max \sum_{i} x_{i} C_{i}$} \\
\hline Property & $\mathrm{Eq}$ & Model & $\begin{array}{c}\text { Lower } \\
\text { bound }\end{array}$ & $\begin{array}{c}\text { Upper } \\
\text { bound }\end{array}$ \\
\hline $\begin{array}{l}\text { Heating } \\
\text { value }\end{array}$ & 2 & $H H V_{B}=\sum_{i} x_{i} H H V_{i}$ & 35 & - \\
\hline $\begin{array}{l}\text { Octane } \\
\text { number }\end{array}$ & 3 & $O N_{B}=\sum_{i} \mathrm{v}_{i} O N_{i}$ & 92 & \\
\hline $\begin{array}{l}\text { Oxygen } \\
\text { percentage }\end{array}$ & 4 & $W o_{B}=\sum_{i} x_{i} W o_{i}$ & 2 & 20 \\
\hline Density & 5 & $\rho_{B}=\sum_{i} \mathrm{v}_{i} \rho_{i}(T)$ & 710 & 770 \\
\hline $\begin{array}{l}\text { Dynamic } \\
\text { viscosity }\end{array}$ & 6 & $\mu_{B}=\exp \sum_{i} x_{i} \ln \mu_{i}$ & $\begin{array}{c}5.7 \\
\mathrm{x} 10^{-4}\end{array}$ & $\begin{array}{c}6.4 \\
\mathrm{x} 10^{-4}\end{array}$ \\
\hline $\begin{array}{l}\text { Reid vapor } \\
\text { pressure }\end{array}$ & 7 & $P_{B}=\sum x_{i} \gamma_{i} P_{i}^{\text {sat }}(T)$ & - & 62 \\
\hline $\begin{array}{l}\text { Mixture } \\
\text { stability }\end{array}$ & 8 & $\frac{d \ln \gamma_{i}}{d x_{i}}+\frac{1}{x_{i}}>0$ & & \\
\hline $\begin{array}{l}\text { Component } \\
\text { fraction }\end{array}$ & 9 & $\sum x_{i}-1=0$ & & \\
\hline
\end{tabular}

\subsection{Decomposition-based solution strategy}

5.1 Sub-problem 1: Stability constraints

The stability constraint is represented by Equation 8 (see Table 1). This constraint establishes the miscibility of liquid mixtures. Each possible pair of chemical forming blend candidates is tested for their stability and the unstable mixtures are eliminated. The blends must contain gasoline and more additives.

\subsection{Sub-problem 2: Product property constraints}

In sub-problem 2, the miscible mixtures are tested further to meet the product requirements. As listed in Table 1, six mixture properties must be satisfied for fuel blends, there are: heating value, octane number, oxygen content, density, viscosity and Reid vapor pressure. Each property is represented by mixture property model, which provide the necessary calculated value. The mixture property models are a combination of linear and non-linear models. Equations 2 to 5 (see Table 1) are using simple linear 
mixing rules, while Equations 6 and 7(see Table 1) are non-linear models. In this stage, the simpler models (Equation 2 - 5) are solved first, followed by viscosity and Reid vapor pressure models.

\subsection{Sub-problem 3}

This final sub-problem involves optimization as shown below,

$$
f_{o b j}=\min \sum x_{i} C_{i}
$$

Subject to

$$
\sum_{x_{G} \geq 0.5} x_{i}-1=0
$$

The objective is to minimize the fuel cost, which the cost is highly depend on the type of chemicals used. The blend ratio is limited only up to $50 \%$ of additives in order to be able used in the existing internal combustion engine without modification.

\subsection{Property models and verification}

Property models are very important in chemical blend design. Use of appropriate property models is crucial because it directly influences the final blend composition. One of the limitations of the computeraided technique is indeed the limitation of the property models that are used. Therefore, this paper highlights the modeling issue related to property constraints and their validation. The properties of liquid chemical blends vary according to the type of blend products. However, several liquid (bulk) mixture properties, such as, density and viscosity are common to many products. Other target properties depend on the specific qualities of the products that need to be enhanced. For instance, the important mixture properties of a fuel blend are Reid vapor pressure (RVP), heating value, octane number and oxygen content for an oxygenated blended fuel.

\subsection{Sub-problem 1: Mixture stability model}

The mixture stability model is used to check the phase stability of binary mixture. The stability test is based on the trend of the Gibbs energy of mixing $\left(\Delta \mathrm{G}^{\mathrm{mix}} / \mathrm{RT}\right)$ and its first and second derivatives.

$$
\frac{\Delta G^{m i x}}{R T}=\sum_{i} x_{i} \ln x_{i}+\frac{G^{E}}{R T}
$$

Where, $G^{\mathrm{E}} / \mathrm{RT}$ represent by,

$$
\frac{G^{E}}{R T}=\sum_{i} x_{i} \ln \gamma_{i}
$$

In order to have a stable single-phase mixture, $\Delta \mathrm{G}^{\text {mix }}$ and its first and second derivatives must be continuous functions of $x_{i}$ and the second derivative must everywhere be positive at constant pressure and temperature.

$$
\frac{d^{2} \Delta G^{m i x}}{d x_{i}^{2}}>0
$$

Equation 12 is extended by substitute the second derivatives of Gibbs energy of mixing and Excess Gibbs energy and gives;

$$
\frac{d \ln \gamma_{i}}{d x_{i}}+\frac{1}{x_{i}}>0
$$

Equation 13 is used in this work to test the stability of binary mixtures. For any binary mixture of identified chemicals, composition and temperature, the activity coefficient, $\gamma_{i}$ can be calculated through any $\mathrm{G}^{\mathrm{E}}$ model (like UNIFAC) and if Equation 13 is satisfied, the blend candidate (binary mixture) is feasible as it is a single phase liquid. Note that depending on the mixture being studied, different $\mathrm{G}^{\mathrm{E}}$-models may need to be used for this constraint. In this paper, however, only the use of the UNIFAC model (which is briefly explained in section 6.2.1) is being illustrated.

\subsubsection{Results of mixture stability test}

Table 2 shows the results of stability test for binary mixtures of gasoline components with ethanol, butanol and MTHF at $298.15 \mathrm{~K}$. All the binary pairs are miscible except for mixtures of heptane/MTHF and iso-octane/MTHF. These binary mixtures are partially miscible at high concentration of MTHF. The stability test is confirmed by liquid-liquid equilibrium (LLE) calculation using Integrated Computer-Aided System (ICAS) software. Figure 2 shows the LLE diagram plotted for the mixture of isooctane/ethanol using ICAS software. Referring to Figure 2, the iso-octane/ ethanol blends are miscible at temperature above $275 \mathrm{~K}$ at any compositions. The stability result presented agreed with the LLE diagram.

Table 2. The phase stability of gasoline components and additives

\begin{tabular}{|c|c|c|c|}
\hline Additive & Ethanol & Butanol & MTHF \\
\hline Hexane & $\mathrm{M}$ & $\mathrm{M}$ & $\mathrm{M}$ \\
\hline Heptane & $\mathrm{M}$ & $\mathrm{M}$ & $\mathrm{P}$ \\
\hline Iso-octane & $\mathrm{M}$ & $\mathrm{M}$ & $\mathrm{P}$ \\
\hline Toluene & $\mathrm{M}$ & $\mathrm{M}$ & $\mathrm{M}$ \\
\hline $\mathrm{p}$-xylene & $\mathrm{M}$ & $\mathrm{M}$ & $\mathrm{M}$ \\
\hline
\end{tabular}

M: Miscible P: partially miscible 


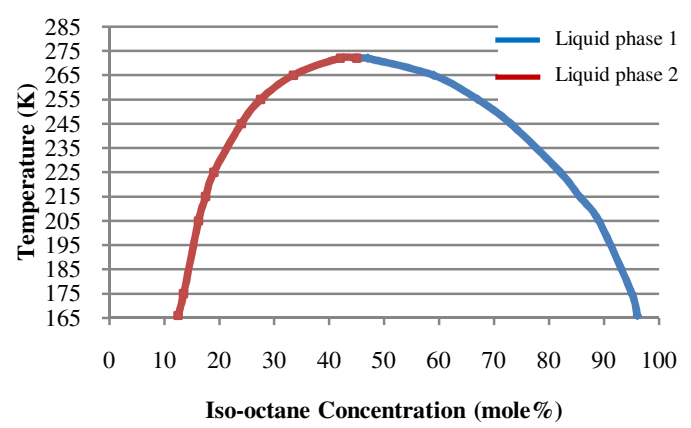

Figure 2: Binary LLE diagram of Iso-octane/Ethanol mixture

However, the binary mixtures involve MTHF could not be verified using this method due to unavailable data of liquid-liquid equilibrium of MTHF.

\subsection{Sub-problem 2: Product property models}

The heating value model, Equation 2 is taken from Clements [9], who compared the predicted and experimental heating values and reported a highest error of 5\%. Equation 3, the model for octane number a linear mixing rules is assumed. Equation 4 is used to predict the oxygen percentage, which can be calculated directly from the component structure and corresponds proportionally to the mole fraction. The density model in Equation 5 is also taken from [9], with percent error is less than 0.7 percent. However, Clements [9] used different empirical constants to predict the density of the pure components. Equation 6 was suggested by Reid and Sherwood [10] to predict the liquid mixture viscosity. The RVP of a non-ideal mixture (gasoline blend) is predicted using modified Raoult's law as shown in Equation 7. This model has been tested for several blends and the results are shown in the next section.

\subsubsection{The Reid vapor pressure model}

The Reid vapor pressure (RVP) is one of the important properties of gasoline. It is defined as the absolute pressure exerted by a mixture at $100^{\circ} \mathrm{F}$. The model used to predict the RVP is based on the modified Raoult's Law, which is calculating the vapor pressure at $100^{\circ} \mathrm{F}$ and given liquid composition. The saturated vapor pressures of the pure components are calculated using Equation 14 and their parameters are taken from ICAS database.

$$
P_{i}^{s a t}(T)=\exp \left(A+\frac{B}{T}+C \ln (T)+D T^{E}\right)
$$

The activity coefficients of the mixture components (needed in eq. 16) are predicted using the UNIFAC group contribution model. In the UNIFAC model, the logarithm of the activity coefficient is given as the sum of two parts: a combinatorial part, which considered the differences in size and shape of molecules in the mixture and a residual part that, accounts for the interactions between the groups in the molecule. The UNIFAC group parameters used in this work are retrieved from Fredenslund, et. al.,[6]. For molecule $i$ in any solution, $\ln \gamma_{i}$ is given as:

$$
\ln \gamma_{i}=\ln \gamma_{i}^{C}+\ln \gamma_{i}^{R}
$$

In order to predict the equilibrium vapor pressure, Equation 7 needs to be rearranged and gives,

$$
y_{i}=\frac{x_{i} \gamma_{i} P_{i}^{s a t}(T)}{P_{B}}
$$

Where the temperature is set at $310.92 \mathrm{~K}\left(100^{\circ} \mathrm{F}\right)$ and calculated vapor fraction, $y_{i}$ must satisfy the condition,

$$
\sum y_{i}-1=0
$$

The calculated vapor pressure, $\mathrm{P}_{\mathrm{B}}$ at $100{ }^{\circ} \mathrm{F}$ is referred to the RVP of the mixture.

\subsubsection{Prediction results}

Table 3 compares the predicted RVP obtained through the UNIFAC model with reported values [11]. Again, as with constraint 8 , any GE-model could be used, but in those papers, we are illustrating the use of the UNIFAC model because of its predictive nature. The UNIFAC model gives satisfactory predictions for the blends for a higher volume percent of additive with average absolute errors of $2-3 \%$. Higher errors are obtained at a lower volume percent of additives. For the case of ethanol, the model tends to underpredict the effect of its presence on the RVP of the gasoline blend by over $3.2 \%$, while in case of iso-propanol, the model tends to overpredict the effect of its presence by less than $2.2 \%$. Overall, the RVP predicted through UNIFAC model gives satisfactory predictions with an average absolute percents error of $3.83 \%$.

Table 3. Predicted and reported of RVP of gasoline containing oxygenated compounds

\begin{tabular}{|l|c|c|c|}
\hline $\begin{array}{c}\text { Gasoline }+ \\
\text { additive }\end{array}$ & $\begin{array}{c}\text { Reported } \\
\text { RVP } \\
(\mathrm{kPa})\end{array}$ & $\begin{array}{c}\text { Predicted } \\
\text { RVP } \\
(\mathrm{kPa})\end{array}$ & $\begin{array}{c}\text { Error } \\
(\%)\end{array}$ \\
\hline $\mathrm{G}+2 \mathrm{E}$ & 25.3 & 23.46 & 7.1 \\
\hline $\mathrm{G}+5 \mathrm{E}$ & 26.4 & 25.14 & 4.9 \\
\hline $\mathrm{G}+10 \mathrm{E}$ & 27.3 & 26.41 & 3.2 \\
\hline $\mathrm{G}+15 \mathrm{E}$ & 27.5 & 26.46 & 3.8 \\
\hline $\mathrm{G}+2 \mathrm{P}$ & 24.0 & 22.43 & 6.6 \\
\hline $\mathrm{G}+5 \mathrm{P}$ & 25.6 & 25.14 & 1.6 \\
\hline $\mathrm{G}+10 \mathrm{P}$ & 25.9 & 26.28 & -1.3 \\
\hline $\mathrm{G}+15 \mathrm{P}$ & 25.9 & 26.52 & -2.2 \\
\hline
\end{tabular}

Gasoline+ volume \% oxygenated, E: Ethanol, P: Iso-Propanol 


\subsection{Results and discussion}

The gasoline blend problem is a mixture design problem. Initially, about 28000 possible blend candidates for gasoline blending with ethanol, butanol and methy tetrahydrofuran. These candidates are generated based on a blending ratio of $1 \%$ volume changes. Only 5049 candidates satisfied the stability constraint in sub-problem 1. Sub-problem 2 reduced further the number of candidates to 1227 , those that satisfy the heating value and octane number constraints. From those 1227 candidates, 754 candidates have an oxygen percentage in the acceptable range, while 715 candidates satisfy the mixture density constraint. Then, the number of potential candidates was reduced significantly, to only 67 remaining blends that satisfying the dynamic viscosity of the desired fuel blend. The number of candidates remains constant after testing for the final property constraint, the RVP, which means that the remaining candidates all satisfy the Reid vapor pressure constraint. In the final sub-problem (subproblem 3), the objective is to find the blend, from among the feasible ones identified, that gives the cheapest cost of gasoline blend. One example of the 67 feasible blend formulations is E5B5, (ternary blend of $5 \%$ volume of each ethanol and butanol in gasoline) which satisfied all the property (target) constraints now needs to be further tested for its behavior in internal combustion engines. Note that the method is also capable of generating multi-chemical blends as well as binary blends.

\subsection{Conclusions}

This paper presents a decomposition based methodology for solving tailor-made liquid chemical blend design problems. The proposed methodology requires the use of multiple mixture property models, which have been carefully selected and when necessary, validated. The product property constraints in the case of a fuel blend consists of heating value, octane number, oxygen percentage, density, dynamic viscosity and the Reid vapor pressure. The model for predicting the Reid vapor pressure has been validated and found to give an overall absolute percent error of $3.83 \%$, while other selected property models also gave predictions with acceptable reliability. The application of the blend design method has been highlighted for the case of a fuel blend design, illustrating the step-by-step reduction of the numbers of alternatives. Current and future work is developing a library of validated property models needed for different blend design problems (such as fuels, lubricants, process fluids). These are implemented together with the decomposition based blend design method in a computer aided framework for carrying out routine (virtual) experiments related to blend design and analysis of blend candidates.

\section{References}

[1] Gani, R. and Brignole, E. A., "Molecular Design of Solvents for Liquid Extraction Based On UNIFAC", Fluid Phase Equilibria, Vol. 13, (1983), pp. $331-340$.

[2] Achenie, L. E. K., Karunanithi, A. T., and Gani, R., "A New Decomposition-Based Computer-Aided Molecular/Mixture Design Methodology for the Design of Optimal Solvents and Solvent Mixtures", Ind. Eng. Chem. Res., Vol. 44, (2005), pp. 4785 4797.

[3] Klein, J. A., Wu, D. T., and Gani, R., "Computer Aided Mixture Design with Specified Property Constraints", European Symposium on Computer Aided Process Engineering-1., Vol. 16, Supplement 1, (1992), pp. S229 - S236.

[4] Gani, R., and Fredenslund, A., "Computer Aided Molecular and Mixture Design with Specified Property Constraints", Fluid Phase Equilibria, Vol. 82, (1993), pp. $39-46$.

[5] Elisa, C., Gani, R. and Ng, K. M., "Design of Formulated Products: A Systematic Methodology", AIChE Journal, (2010). DOI: 10.1002/aic.12458

[6] Fredenslund, A., Rasmussen, P. and Magnussen, T., "UNIFAC Parameter Table for Prediction of Liquid-Liquid Equilibria”, Ind. Eng. Chem. Process Des. Dev., Vol. 20, No.2, (1981), pp. 331 - 339.

[7] Türkay, M., and Grossmann, I. E., "Logic-based MINLP Algorithm for the Optimal Synthesis of Process Network", Computers Chemical Engineering, Vol. 20, No. 8, (1996), pp. 959 - 978.

[8] Geoffrion, A. M., "Generalized Benders Decomposition", Journal of Optimization Theory and Applications, Vol. 10, No. 4, (1972).

[9] Clements, L. D. "Blending Rules for Formulating Biodiesel Fuel”, (1991).

[10] Reid, R. C., and Sherwood, T. K, The Properties of Gases and Liquids, New York, McGraw Hill, 1958, Chap. 9, pp $441-449$.

[11] Hatzioannidis, I., Voutsas, E. C., Lois, E., and Tassios, D. P., "Measurement and Prediction of Reid Vapor Pressure of Gasoline in the Presence of Additives", Journal of Chemical Engineering Data, Vol. 43, (1998), pp 386 - 392. 